\title{
Outcomes of Cardiopulmonary Resuscitation and Estimation of Healthcare Costs in Potential 'Do Not Resuscitate' Cases
}

*Akhwand S. Ahmad, Sayed Mudasser, Muhammad N. Khan, Hafiz N. H. Abdoun

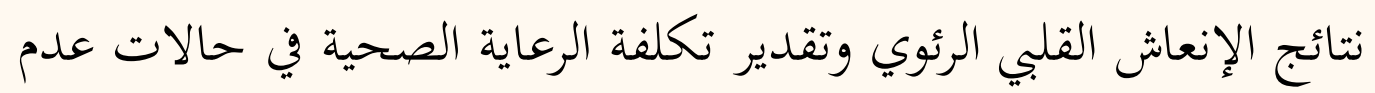

الإنعاش المحتملة

$$
\text { أخواند شكيل أحمد، سيد مدثر، محمد نادر خان، حافظ نجم الدين حسن }
$$

ABSTRACT: Objectives: Cardiopulmonary resuscitation (CPR) is a life-saving procedure which may fail if applied unselectively. 'Do not resuscitate' (DNR) policies can help avoid futile life-saving attempts among terminally-ill patients. This study aimed to assess CPR outcomes and estimate healthcare costs in potential DNR cases. Methods: This retrospective study was carried out between March and June 2014 and included 50 adult cardiac arrest patients who had undergone CPR at Sultan Qaboos Hospital in Salalah, Oman. Medical records were reviewed and treating teams were consulted to determine DNR eligibility. The outcomes, clinical risk categories and associated healthcare costs of the DNR candidates were assessed. Results: Two-thirds of the potential DNR candidates were $\geq 60$ years old. Eight patients (16\%) were in a vegetative state, 39 (78\%) had an irreversible terminal illness and $43(86 \%)$ had a low likelihood of successful CPR. Most patients (72\%) met multiple criteria for DNR eligibility. According to clinical risk categories, these patients had terminal malignancies (30\%), recent massive strokes (16\%), end-stage organ failure (30\%) or were bed-bound (50\%). Initial CPR was unsuccessful in 30 patients (60\%); the remaining 20 patients $(40 \%)$ were initially resuscitated but subsequently died, with $70 \%$ dying within 24 hours. These patients were ventilated for an average of 5.6 days, with four patients (20\%) requiring $>15$ days of ventilation. The average healthcare cost per patient was USD \$1,958.9. Conclusion: With careful assessment, potential DNR patients can be identified and futile CPR efforts avoided. Institutional DNR policies may help to reduce healthcare costs and improve services.

Keywords: Cardiopulmonary Resuscitation; Medical Futility; Do Not Resuscitate Orders; Persistent Vegetative State; Terminally Ill; Healthcare Costs; Oman.

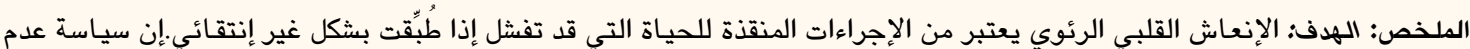

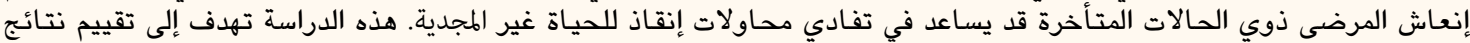

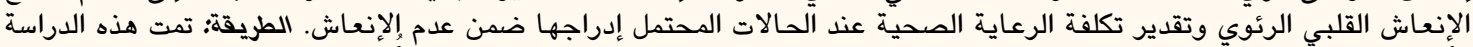

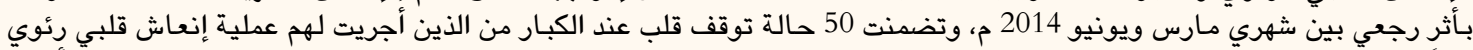

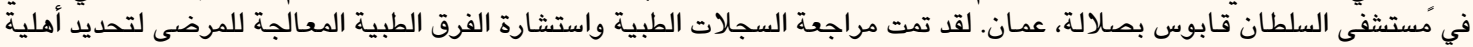

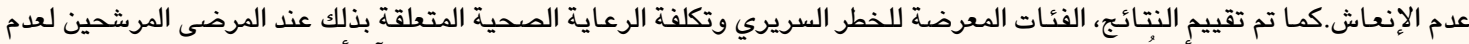

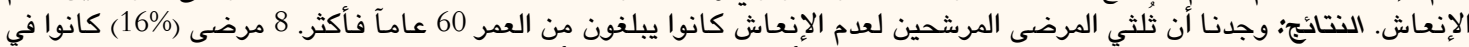

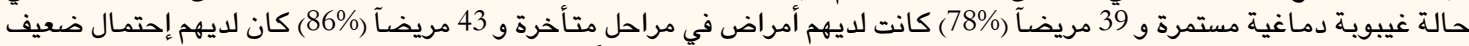

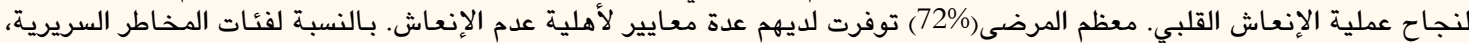

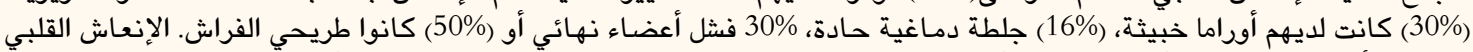

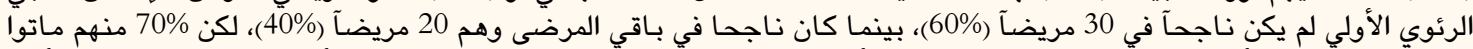

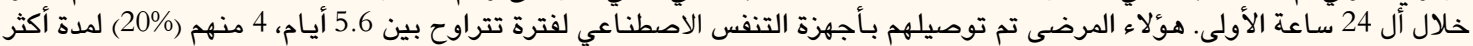

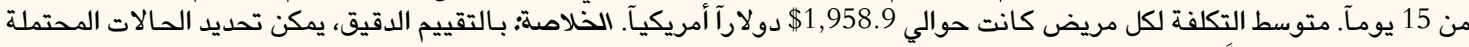

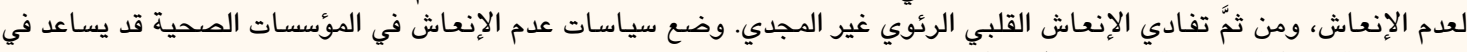

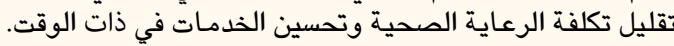

مفتاح الكلمات: الإنعاش القلبي الرئوي؛ عدم الجدوي الطبية؛ التوصية بعدم الإنعاش؛ غيبوية دماغية مستمرة؛ مرض عُضال؛ تكلفة الرعاي الصحية؛ عمان.

\section{Advances in KNOWledge}

While cardiopulmonary resuscitation (CPR) techniques have advanced over time, these life-saving measures may still be futile for certain patients. This study indicates very poor CPR outcomes and high associated healthcare costs among potential 'do not resuscitate' (DNR) candidates at a secondary care hospital in Oman. 


\section{Application to Patient Care}

Many hospitals and medical institutions still lack official DNR policies or clear guidelines to identify DNR cases. The results of this study indicate that potential DNR patients can be identified according to certain criteria. Institutional DNR policies are recommended to save terminally-ill patients from undue trauma and reduce the burden on available healthcare services.

C ardiopulmonary resuscitation (CPR) is an emergency medical procedure whereby external measures, including chest compression, artificial respiration or defibrillation, are carried out in an attempt to restore breathing and spontaneous circulation in a patient whose heart and/or breathing have stopped. Important milestones in the history of CPR include the implementation of mouth-to-mouth resuscitation by William Tossach in 1732, the first successful closed-chest cardiac massage by Friedrich Maass in 1892, the first successful openchest defibrillation by Claude Beck and his team in 1947 and the first successful closed-chest human defibrillation by Paul Zoll and colleagues in 1955. ${ }^{1-5}$ Chest compressions were established as part of CPR procedures by William Kouwenhoven in $1958 .{ }^{6}$ The American Heart Association (AHA) formally endorsed CPR in 1963 and produced standardised CPR guidelines in $1966 .^{7}$

Prompt CPR is life-saving in select cases. However, the chances of a patient surviving following $\mathrm{CPR}$ measures vary depending on the cause and circumstances of the cardiac arrest. With in-hospital CPR, the chances of survival-to-discharge are 15-20\%, while out-of-hospital CPR carries an even lower rate of survival-to-discharge (5-10\%). ${ }^{8-10}$ Survival rates decrease even further for the elderly, nursing home residents or those with multiple medical problems. ${ }^{11}$ For advanced cancer patients, survival-to-discharge following in-hospital CPR is approximately $6 \%{ }^{9}$ Furthermore, the process of CPR itself is not without risk. Rib fractures, damage to internal organs, hypoxic brain damage and increased risk of physical disability are potential CPR-associated complications. ${ }^{12}$ Following CPR, a patient will normally require support in an intensive care unit (ICU); fatal anoxic encephalopathy or respiratory complications may arise from long-term ventilator dependence. ${ }^{13}$ Unsuccessful CPR may also lead to an undignified and/or traumatic death, as well as creating an unnecessary financial burden on the medical services system.

By 1976, as the limitations of CPR became known, the potential benefits of 'do not resuscitate' (DNR) orders for terminally-ill patients began to be discussed. ${ }^{14}$ Carrying out a DNR order means that no resuscitative measures are undertaken if the patient undergoes a cardiopulmonary arrest. Cardiac or respiratory arrest is an inevitable part of dying; thus, theoretically, CPR measures can be used indefinitely on every individual. It is therefore essential to identify patients for whom cardiopulmonary arrest represents the terminal event in their illness, as CPR is inappropriate for these patients. In circumstances where the decision is made not to perform CPR, an order for DNR-sometimes termed 'do not attempt resuscitation' or 'allow natural death'-is inserted into the patient's records. Such orders are intended to prevent inappropriate, futile or undesired CPR attempts.

The General Medical Council of the UK recommends not attempting CPR if resuscitation is likely to be unsuccessful (i.e. if cardiac or respiratory arrest is an expected part of the dying process) or if successful CPR is not clinically appropriate (i.e. due to likely clinical outcomes). ${ }^{15}$ In Wisconsin, USA, legislature exists which permits physicians to dispense DNR orders for the following types of adult patients: those with terminal illnesses; those with medical conditions that indicate CPR would be unsuccessful in restoring cardiac or respiratory function; those who would shortly undergo repeated cardiac or pulmonary failure before death despite CPR measures; or those who would suffer significant pain or harm as a result of the CPR measures, eclipsing the possibility that CPR measures might successfully and indefinitely restore cardiac or respiratory function. ${ }^{16}$ In essence, DNR orders are implemented if the clinical team believes that CPR is medically futile or if CPR will, at the most, prolong the process of dying. Additionally, CPR may not be appropriate if it is unlikely to lead to a meaningful recovery or is carried out on a vegetative patient.

In Oman, as with many other countries, no legislation regarding DNR orders currently exists. Previous research conducted in the country has focused on DNR orders in relation to terminallyill cancer patients and in the neonatal ICU of a tertiary care centre. ${ }^{17,18}$ This study aimed to assess the outcomes and estimate the associated healthcare costs of CPR among potential DNR patients admitted to the Sultan Qaboos Hospital (SQH), a secondary care centre in Salalah, Oman.

\section{Methods}

This retrospective study was carried out from March to June 2014 at SQH and included all admitted adult 
medical patients $>18$ years old who had experienced cardiac arrest, received at least one attempt at CPR (referred to as index CPR) and were potential DNR candidates. Patients whose medical history was unknown, who presented with cardiac arrest or those with an uncertain DNR eligibility status were excluded from the study. Similarly, patients who were resuscitated in hospital areas other than the general medical ward or medical critical care area (e.g. emergency, surgical or gynaecological departments) were not included. A total of 81 patients at SQH were initially determined to have suffered a cardiac arrest and undergone CPR. Of those, 50 met the inclusion criteria and were included in the study. Another 19 patients were subsequently identified, but were excluded from the study due to a lack of information on the part of the consulting physician regarding the status of the patient prior to CPR.

Three criteria were determined to indicate DNR eligibility: (1) the clinical condition of the patient indicated that resuscitation would be medically futile as it would either not restore cardiac and respiratory function or would do so only briefly with a subsequent need for further CPR attempts; (2) the patient was in a persistent vegetative state with no reasonable possibility of regaining cognitive function; or (3) the patient had been diagnosed with an irreversible terminal illness whereby cardiopulmonary arrest was considered a natural consequence of the disease process. The demographic and clinical data of the DNR candidates were collected from medical records and via consultations with the treating teams. In some cases, the researchers had been directly involved in the care of a particular patient and were able to categorise DNR eligibility without further consultation. The potential DNR cases, once identified, were assessed for immediate and long-term CPR outcomes. Additionally, the following pre-existing conditions (i.e. present at admission) were deemed clinical risk categories predictive of a poor prognosis and were used to further classify the patients: terminal incurable malignancy, recent massive stroke, end-stage organ failure and being bed-bound.

Healthcare costs (including expenses related to medications, laboratory investigations, imaging studies, procedures such as tracheostomies or chest tube placements and hospital stay) were approximated using information collected from a comprehensive healthcare information management system (e-Government Al Shifa System, Ministry of Health, Muscat, Oman). Unfortunately, data on certain items were not available via this system (e.g. screening cultures, nutritional supplements and disposable products such as catheters, central lines, endotracheal and feeding tubes, urinary catheters and drainage bags) and thus the costs of these items were not included in the estimation. Data were analysed with simple statistical calculations performed manually using Microsoft Excel 2010 (Microsoft, Inc., Redmond, Washington, USA).'

This study was approved by the Ethical Committee of the Directorate General of Health, Ministry of Health, Salalah.

Table 1: Characteristics of potential 'do not resuscitate' patients undergoing at least one attempt at cardiopulmonary resuscitation at Sultan Qaboos Hospital, Salalah, Oman $(\mathrm{N}=50)$

\begin{tabular}{|c|c|c|}
\hline \multirow[t]{2}{*}{ Characteristic } & \multicolumn{2}{|c|}{ n (\%) } \\
\hline & $\begin{array}{l}\text { Total } \\
(\mathbf{n}=50)\end{array}$ & $\begin{array}{c}\text { Index CPR } \\
\text { survivors } \\
(\mathrm{n}=20)\end{array}$ \\
\hline \multicolumn{3}{|l|}{ Gender } \\
\hline Male & $29(58)$ & $13(65)$ \\
\hline Female & $21(42)$ & 7 (35) \\
\hline $\begin{array}{l}\text { Mean age in } \\
\text { years (range) }\end{array}$ & 64. (26-98) & $61(26-79)$ \\
\hline \multicolumn{3}{|l|}{ Nationality } \\
\hline Omani & $44(88)$ & $19(95)$ \\
\hline Other & $6(12)$ & $1(5)$ \\
\hline $\begin{array}{l}\text { Mean hospital } \\
\text { stay in days } \\
\text { prior to index } \\
\text { CPR (range) }\end{array}$ & $33(0-320)$ & $34(0-236)$ \\
\hline \multicolumn{3}{|c|}{ DNR eligibility category } \\
\hline $\begin{array}{l}\text { Vegetative state } \\
{[95 \% \text { CI }]}\end{array}$ & $8(16)[5.9-26.1]$ & $3(15)[0-30.6]$ \\
\hline $\begin{array}{l}\text { Terminal } \\
\text { illness [95\% CI] }\end{array}$ & 39 (78) [66.6-79.4] & $12(60)$ [38.5-81.5] \\
\hline $\begin{array}{l}\text { Low likelihood } \\
\text { of CPR success } \\
{[95 \% \text { CI }]}\end{array}$ & 43 (86) [76.9-95.6] & $16(80)$ [62.5-97.5] \\
\hline \multicolumn{3}{|l|}{ Ventilation } \\
\hline Before index CPR & $22(44)$ & $6(30)$ \\
\hline After index CPR & $20(40)$ & $20(100)$ \\
\hline \multicolumn{3}{|c|}{ Clinical risk category } \\
\hline $\begin{array}{l}\text { Bed-bound } \\
\text { [95\% CI] }\end{array}$ & 25 (50) [36.1-63.9] & 11 (55) [33.2-76.8] \\
\hline $\begin{array}{l}\text { Malignancy } \\
{[95 \% \text { CI }]}\end{array}$ & 15 (30) [17.3-42.7] & $5(25)[6.0-44.0]$ \\
\hline Stroke [95\% CI] & $8(16)[5.9-26.1]$ & $3(15)[0-30.6]$ \\
\hline $\begin{array}{l}\text { Organ failure } \\
{[95 \% \text { CI }]}\end{array}$ & 15 (30) [17.3-42.7] & $4(20)[2.5-37.5]$ \\
\hline
\end{tabular}

$C P R=$ cardiopulmonary resuscitation; $D N R=$ 'do not resuscitate'; $C I=$ confidence interval. 


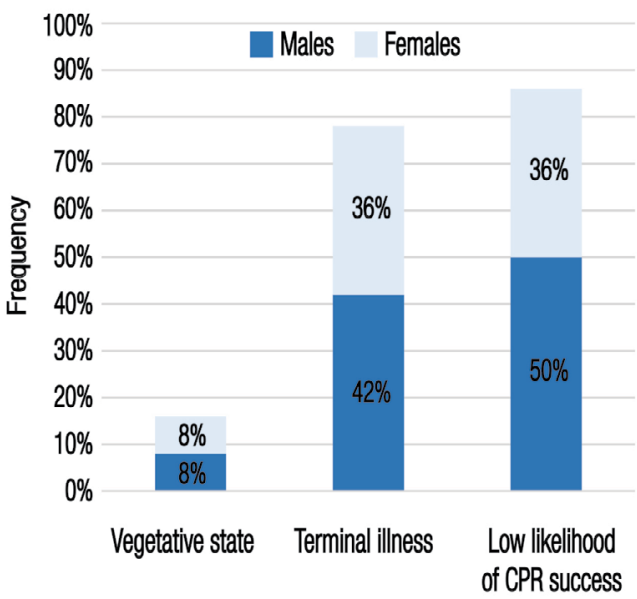

Figure 1: Frequency of 'do not resuscitate' (DNR) eligibility category by gender among potential DNR patients undergoing at least one attempt at cardiopulmonary resuscitation at Sultan Qaboos Hospital, Salalah, Oman $(\mathrm{N}=50)$.

$C P R=$ cardiopulmonary resuscitation

\section{Results}

Of the 50 potential DNR cases included in the study, 29 (58\%) were male and $21(42 \%)$ were female. The patients ranged in age between $26-98$ years old; 33 patients $(66 \%)$ were $\geq 60$ years old and four patients (8\%) were $<50$ years old. The average hospital stay duration before the index CPR was 33 days (range: three hours-320 days) [Table 1]. A total of 22 patients (44\%) had already been ventilated for an average of 10 days when index CPR was required (range: 10 minutes-35 days; aggregate: 218 days). Three other patients also received non-invasive ventilation, on average for two days prior to index CPR. Nine patients (18\%) were in the general medical ward when they experienced cardiac arrest, while all other patients (82\%) were already in the critical care area. Approximately onethird of the patients $(n=17 ; 34 \%)$ were septic on admission and 15 patients (30\%) became septic later.

In terms of DNR eligibility criteria, eight patients (16\%) were in a vegetative state, 39 (78\%) had an irreversible terminal illness and 43 (86\%) met the criteria of low clinical likelihood of CPR success [Figure $1]$. However, the majority of the patients $(n=36$; $72 \%)$ met multiple criteria for DNR eligibility. Less than one-third of the patients ( $\mathrm{n}=14 ; 28 \%)$ met only a single DNR criterion: one patient (2\%) was vegetative, three (6\%) had been diagnosed with terminal illnesses and 10 (20\%) had a low likelihood of CPR success. None of the patients had provided DNR directives in advance.

Risk factors present on admission which were deemed to predict a poor CPR outcome included endstage malignancies $(\mathrm{n}=15 ; 30 \%)$, recent massive strokes
Table 2: Clinical risk categories of potential 'do not resuscitate' patients undergoing at least one attempt of cardiopulmonary resuscitation at Sultan Qaboos Hospital, Salalah, Oman $(\mathrm{N}=50)$

\begin{tabular}{lc} 
Category & $\mathbf{n}(\mathbf{\%})$ \\
Malignancy & $\mathbf{1 5}(\mathbf{3 0})$ \\
Lung & $3(20)$ \\
Prostate & $2(13)$ \\
Stomach & $2(13)$ \\
Hepatocellular carcinoma & $2(13)$ \\
Rectum & $1(7)$ \\
Colon & $1(7)$ \\
Glioblastoma multiforme & $1(7)$ \\
Chronic lymphocytic leukaemia & $1(7)$ \\
Liver mass* & $1(7)$ \\
Mediastinal mass** & $1(7)$ \\
Organ failure & $\mathbf{1 5}(30)$ \\
Cardiac & $6(40)$ \\
Pulmonary & $5(33)$ \\
Liver & $4(27)$ \\
Bed-bound & $25(50)^{+}$ \\
Multifactorial & $12(48)$ \\
Previous stroke-induced & $8(32)$ \\
Dementia-induced & $5(20)$ \\
Fracture-induced & $3(12)$ \\
Acute or recent stroke & $\mathbf{8 ( 1 6 )}$ \\
infarct & $4(50)$ \\
Intracerebral haemorrhage & $25)$ \\
\hline &
\end{tabular}

*These masses were considered malignant although the patients did not give consent for confirmatory biopsies. ${ }^{+}$These patients had overlapping causes for their bed-bound status.

( $\mathrm{n}=8 ; 16 \%$ ), being bed-bound with poor functional status ( $\mathrm{n}=25 ; 50 \%$ ) or chronic end-stage organ failure $(\mathrm{n}=15 ; 30 \%)$. These clinical risk categories overlapped with each other. Among the eight stroke victims, six $(75 \%)$ had brain infarcts while two (25\%) had intracerebral haemorrhages. Four of the stroke victims (50\%) had atrial fibrillation, although they had either stopped taking or had never taken anticoagulants. Of the patients who were bed-bound, 10 cases (40\%) had overlapping risk conditions: recent massive stroke $(\mathrm{n}=4 ; 16 \%)$, terminal malignancy $(\mathrm{n}=4 ; 16 \%)$ and advanced cardiac failure/crippling chronic obstructive pulmonary disease $(n=2 ; 8 \%)$. However, bed-bound 
Table 3: Estimated healthcare costs of potential 'do not resuscitate' patients who survived at least one attempt at cardiopulmonary resuscitation at Sultan Qaboos Hospital, Salalah, Oman $(\mathrm{N}=20)$

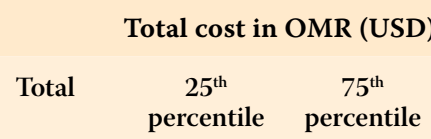
IQR

Variable

\begin{tabular}{|c|c|c|c|c|}
\hline Medications & $\begin{array}{c}4,698.0 \\
(\$ 12,215.0)\end{array}$ & - & $\begin{array}{c}117.5 \\
(\$ 305.5)\end{array}$ & $\begin{array}{c}117.5 \\
(\$ 305.5)\end{array}$ \\
\hline $\begin{array}{l}\text { Laboratory } \\
\text { investigations }\end{array}$ & $\begin{array}{c}4,120.0 \\
(\$ 10,712.0)\end{array}$ & - & $\begin{array}{c}285.5 \\
(\$ 742.3)\end{array}$ & $\begin{array}{c}285.5 \\
(\$ 742.3)\end{array}$ \\
\hline $\begin{array}{l}\text { Imaging } \\
\text { studies }\end{array}$ & $\begin{array}{c}710.0 \\
(\$ 1,846.0)\end{array}$ & - & $\begin{array}{c}56.5 \\
(\$ 146.9)\end{array}$ & $\begin{array}{c}56.5 \\
(\$ 146.9)\end{array}$ \\
\hline $\begin{array}{l}\text { Minor } \\
\text { procedures }\end{array}$ & $\begin{array}{c}450.0 \\
(\$ 1,170.0)\end{array}$ & - & - & - \\
\hline $\begin{array}{l}\text { Hospital stay } \\
\text { in an ICU/ } \\
\text { HDU }\end{array}$ & $\begin{array}{c}5,090.0 \\
(\$ 13,234.0)\end{array}$ & $\begin{array}{c}40.0 \\
(\$ 104.0)\end{array}$ & $\begin{array}{c}300.0 \\
(\$ 780.0)\end{array}$ & $\begin{array}{c}260.0 \\
(\$ 780.0)\end{array}$ \\
\hline $\begin{array}{l}\text { Aggregate } \\
\text { cost }\end{array}$ & $\begin{array}{c}15,068.0 \\
(\$ 39,178.0)\end{array}$ & - & - & - \\
\hline $\begin{array}{l}\text { Average cost } \\
\text { per patient }\end{array}$ & $\begin{array}{c}753.4 \\
(\$ 1,958.9)\end{array}$ & $\begin{array}{c}40.0 \\
(\$ 104.0)\end{array}$ & $\begin{array}{c}848.0 \\
(\$ 2,204.8)\end{array}$ & $\begin{array}{c}808.0 \\
(\$ 2,100.8)\end{array}$ \\
\hline
\end{tabular}

$O M R=$ Omani riyals; $I Q R=$ interquartile range; $I C U=$ intensive care unit $;$ $H D U=$ high dependency unit .

status was a stand-alone risk for the remaining 15 bedbound patients (60\%). Among all of the bed-bound patients, the overlapping causes of immobility included previous strokes, $(\mathrm{n}=8 ; 32 \%)$, advanced dementia $(\mathrm{n}=$ $5 ; 20 \%)$, fractures of the femur or pelvis $(n=3 ; 12 \%)$ or a multifactorial cause $(n=12 ; 48 \%)$ including senility, severe osteoarthritis, degenerative spine disease and diabetes with neurovascular complications [Table 2].

The majority of patients could not be revived during index CPR ( $\mathrm{n}=30 ; 60 \%)$. The remaining 20 patients (40\%) were resuscitated successfully with index CPR but subsequently died; 14 patients (70\%) died within 24 hours and only six (30\%) survived more than 24 hours (range: $1-31$ days). All of these patients required post-CPR ventilator support and intensive care; they remained on ventilators for an average of 5.6 days (aggregate: 112 days) before dying. Four patients (20\%) survived $>15$ days but remained ventilator-dependent. Only one of the patients was taken off the ventilator before death; she was a 54-year-old woman who had been vegetative for eight months and had been weaned onto a T-piece after 16 days of ventilation, despite still being on vasopressors. She arrested again four days later and underwent three further CPR attempts in the following 20 hours before dying. All of these patients underwent yet another CPR attempt prior to death; three patients (15\%) underwent resuscitation three times following the index CPR. Six of the index CPR survivors $(30 \%)$ had been on a ventilator prior to cardiac arrest for a mean duration of 10 days (range: 4-15 days).

Table 3 shows the estimated post-resuscitation healthcare costs for the index CPR survivors. The total cost was approximately Omani riyals (OMR) 15,068.0 (USD \$39,178.0), with an average cost of OMR 753.0 (USD \$1,958.9) per patient. Patients with prolonged hospital stays with ventilator support were responsible for most of the costs; one-third of costs were attributed solely to stays in high-care units alone.

\section{Discussion}

According to Lipsky, four possible indications exist for dispensing a DNR order: futility of treatment, poor quality of life, patient wishes and cost. ${ }^{19}$ In the current study, three criteria were used to categorise patients as potential DNR cases. While two of these criteria are relatively straightforward to assess (vegetative state or terminal illness), determining whether CPR is likely to be successful depends on the clinical judgment of the treating physician. Usually, the decision is not difficult, especially as the patient approaches a terminal state. However, some cases may be more complicated. In the current study, the majority of patients met more than one criterion for DNR eligibility; most of these patients were considered eligible for DNR due to both a terminal illness and a low chance of CPR success. However, no comparative data from other studies could be found. According to Wenger et al., DNR orders are more frequently issued to older patients, those with dementia and women. ${ }^{20}$ While very few of the patients in the current study were below the age of 50 years old, not many of the patients suffered from dementia and there were more male cases than female.

In the current study, patients were assessed according to four clinical risk categories deemed predictive of a poor prognosis. Half of the cohort were bed-bound, although many of these patients also fell into other risk factors. The term bed-bound is clinically vague; nevertheless, it appears useful for its additive risk due to the predisposition of bed-bound patients to develop severe infections, including aspiration pneumonia, urinary tract infections, infected pressure sores and hospital-acquired infections. Bed-bound patients are also prone to other conditions such as venous thromboembolisms, poor nutrition and bleeding due to antithrombotic administration. Sepsis was also a major factor among the subjects in the current study. As it is usually treatable, it was not included as a risk category; however, with an underlying critical illness, it can be fatal. While each patient is different, certain negative prognostic features 
such as the ones used in the current study may serve to translate into a simplified DNR score. Further research is recommended in this area.

It is important to note that none of the potential DNR patients in the current study survived even if they were successfully resuscitated during index CPR. In a study of ICU patients who underwent CPR after cardiopulmonary arrest, Tian et al. calculated an overall survival-to-discharge rate of $15.9 \% .{ }^{21}$ However, patients on vasopressors were half as likely to survive and mechanical ventilation and older age ( $\geq 65$ years old) were associated with even lower rates of survival. More than half of the survivors were discharged to rehabilitation centres and only 3.9\% were discharged home..$^{21}$ In comparison, the findings of the current study may seem disappointing; nevertheless, it is important to note that the patients in Tian et al.s study were not categorised as eligible for a DNR order. Appropriate case selection is therefore a significant factor in guiding CPR prognosis.

In the present study, survivors of the index CPR all required prolonged ventilatory support, with several patients remaining on a ventilator for over 24 hours. Prolonged ICU care and mechanical ventilation is potentially a source of suffering for both the patient and their family; this type of care is also labourintensive on the part of healthcare staff. Additionally, these patients require beds in ICUs or other high-care areas, which are often in finite supply. Almost half of the cohort in the current study had already been on ventilatory support prior to index CPR for a significant duration of time (aggregate: 218 days) and were already in a critical care area before the initiation of index CPR. Assuming these patients had had DNR orders to begin with, a ceiling-of-care, short of ventilation, could have been established, potentially increasing available resources for other patients. Overall, the estimated cost of post-resuscitation care in the current study was very high; however, it is important to note that the actual total costs involved with futile or inappropriate care of terminally-ill patients is likely much higher.

Patients with a DNR order deserve the same standard of care as any other patient, short of CPR; in addition, DNR orders should be revoked if clinical conditions change. Unfortunately, there is evidence that DNR orders are often broadly applied to other therapies. Beach et al. found that patients with a DNR order were less likely to be transferred to an ICU or to be intubated and that their treating physicians were less willing to draw blood cultures, place central lines or prescribe blood transfusions. ${ }^{22}$ Brizzi et al. reported that negative prognostic factors such as advanced age, low consciousness levels, history of a previous stroke, midline shift or intraventricular haemorrhage led to a DNR order among patients with intracerebral haemorrhage; moreover, DNR orders were independently associated with a 3.5-fold increase in one-month mortality. ${ }^{23}$ In this case, early DNR orders may have been used as a justification for an overall decrease in the aggressiveness of care, leading to higher mortality. Similarly, Scarborough et al. reported that preoperatively-issued DNR orders were a risk factor for mortality after emergency general surgery; this is likely because such patients do not undergo aggressive treatment for major postoperative complications. ${ }^{24}$

Policies and attitudes towards DNR orders vary according to country. In the UK, DNR orders remain clinical decisions; however such decisions should be individualised with an avoidance of blanket policies and attempts should be made to involve patients in the decision-making process. ${ }^{25}$ In the USA, the situation is different as there is a presumption in favour of resuscitation if a DNR order is not already in place; if made, the orders are established in consultation with the patient or their legal representative. ${ }^{26}$ The AHA recommends resuscitation for all patients in cardiac arrest unless there is a valid DNR order or if resuscitation is physiologically futile (e.g. if a patient shows signs of irreversible death). ${ }^{27}$ In 1976, the Natural Death Act was enacted in California, USA, to protect a patient's right to opt for a natural death without CPR. ${ }^{28}$ Several years later, the Patient SelfDetermination Act was implemented to ensure that healthcare institutions in the USA would recognise and conform to advance DNR directives. ${ }^{28}$ In Taiwan, most terminal patients were taken home to die in accordance with local customs until 2000, when the Hospice Care Law which includes legislation regarding natural death was enacted. ${ }^{29}$ Subsequently, DNR orders were found to be on the rise among Taiwanese patients who had been ill for a long period of time or who had solid tumours. ${ }^{30}$ In Japan, physicians can institute DNR orders without consulting the patient's family if they feel that CPR is unjustified and futile. ${ }^{31}$ There are no national guidelines regarding DNR orders in Denmark; however, patients must generally give informed consent before DNR orders are implemented. ${ }^{32}$ In Saudi Arabia, a DNR order can only be applied in consultation with the patient's family. ${ }^{33}$ Overall, CPR seems to be the only medical intervention whereby consent is automatically assumed-based on implied consent for emergency treatment-and a medical order required in order to withhold its administration.

The authors of the current study favour the approach towards DNR implemented in the UK. While CPR is not indicated in every case of cardiac arrest and natural death should be allowed in certain circumstances, the patients and their families should 
be involved in the discussion. It has been suggested that changing the wording of DNR orders to 'allow natural death' may make the order more descriptive and less threatening. ${ }^{34}$ Nevertheless, while communication with patients and their families can facilitate care planning, the extent that the message is understood may be affected by cultural and racial factors; according to Mack et al., end-of-life discussions (terminal illness awareness, treatment preferences and DNR orders) benefited Caucasian patients but not African American patients. ${ }^{35}$

One of the major limitations of this study was the retrospective classification of DNR eligibility status based on data collected from medical records and consultations with each patient's treating team. This process of case selection raises concerns of potential bias in case selection. Additionally, as this was a singlecentre study, the results cannot be generalised to other institutions. However, despite these limitations, the findings of this study imply that CPR is ineffective in selected cases which can be identified with a set of predetermined criteria.

\section{Conclusion}

Although often life-saving, CPR is not beneficial in many cases. Allowing death to occur naturally can save undue suffering on the part of a terminally-ill patient and their family and reduce the burden on the healthcare system as a whole. Within institutions, the adoption of a DNR policy may reduce healthcare costs both directly and indirectly, as it establishes grounds for the concept of ceiling-of-care and appropriate case-specific treatment options.

\section{CONFLICT OF INTEREST}

The authors declare no conflicts of interest.

\section{References}

1. Tossach WA. A man dead in appearance recovered by distending the lungs with air. Med Essays Obs 1744; 5:605-8.

2. Taw RL Jr. Dr. Friedrich Maass: 100th anniversary of "new" CPR. Clin Cardiol 1991; 14:1000-2. doi: 10.1002/clc.49601 41211 .

3. Hermreck AS. The history of cardiopulmonary resuscitation. Am J Surg 1988; 156:430-6. doi: 10.1016/S0002-9610(88) 80521-X.

4. Beck CS, Pritchard WH, Feil HS. Ventricular fibrillation of long duration abolished by electric shock. J Am Med Assoc 1947; 135:985. doi: 10.1001/jama.1947.62890150005007a.

5. Zoll PM, Linenthal AJ, Gibson W, Paul MH, Norman LR. Termination of ventricular fibrillation in man by externally applied electric countershock. N Engl J Med 1956; 254:727-32. doi: 10.1056/NEJM195604192541601.
6. Safar P, Brown TC, Holtey WJ, Wilder RJ. Ventilation and circulation with closed-chest cardiac massage in man. JAMA 1961; 176:574-6. doi: 10.1001/jama.1961.03040200010003.

7. American Heart Association. History of CPR: Highlights of CPR dating back to the 1700's. From: www.heart.org/HEARTORG/ CPRAndECC/WhatisCPR/CPRFactsandStats/History-ofCPR_UCM_307549_Article.jsp Accessed: Oct 2015.

8. Sandroni C, Nolan J, Cavallaro F, Antonelli M. In-hospital cardiac arrest: Incidence, prognosis and possible measures to improve survival. Intensive Care Med 2007; 33:237-45. doi: 10.1007/s00134-006-0326-z.

9. Reisfield GM, Wallace SK, Munsell MF, Webb FJ, Alvarez ER, Wilson GR. Survival in cancer patients undergoing in-hospital cardiopulmonary resuscitation: A meta-analysis. Resuscitation 2006; 71:152-60. doi: 10.1016/j.resuscitation.2006.02.022.

10. Herlitz J, Bång A, Gunnasson J, Engdahl J, Karlson BW, Lindqvist J, et al. Factors associated with survival to hospital discharge among patients hospitalised alive after out of hospital cardiac arrest: Change in outcome over 20 years in the community of Göteborg, Sweden. Heart 2003; 89:25-30. doi: 10.1136/heart.89.1.25.

11. Ehlenbach WJ, Bamato AE, Curtis JR, Kreuter W, Koepsell TD, Deyo RA, et al. The epidemiology of in-hospital cardiopulmonary resuscitation in older adults: 1992-2005. N Engl J Med 2009; 361:22-31. doi: 10.1056/NEJMoa0810245.

12. Krischer JP, Fine EG, Davis JH, Nagel EL. Complications of cardiac resuscitation. Chest 1987; 92:287-91. doi: 10.1378/chest. 92.2.287.

13. Myerburg RJ, Conde CA, Sung RJ, Mayorga-Cortes A, Mallon SM, Sheps DS, et al. Clinical, electrophysiologic and hemodynamic profile of patients resuscitated from prehospital cardiac arrest. Am J Med 1980; 68:568-76. doi: 10.1016/00029343(80)90307-1.

14. Rabkin MT, Gillerman G, Rice NR. Orders not to resuscitate. New Engl J Med 1976; 295:364-6. doi: 10.1056/ NEJM197608122950705.

15. General Medical Council. Treatment and care towards the end of life: Good practice in decision making. From: www.gmc-uk. org/guidance/ethical_guidance/end_of_life_care.asp Accessed: Oct 2015.

16. Wisconsin State Legislature. Advance directives: Subchapter III - Do-not-resuscitate orders. From: docs.legis.wisconsin.gov/ statutes/statutes/154/III/17/4 Accessed: Oct 2015.

17. Faris M. Clinical estimation of survival and impact of other prognostic factors on terminally ill cancer patients in Oman. Support Care Cancer 2003; 11:30-4. doi: 10.1007/s00520-0020401-0.

18. da Costa DE, Ghazal H, Al Khusaiby S. Do not resuscitate orders and ethical decisions in a neonatal intensive care unit in a Muslim community. Arch Dis Child Fetal Neonatal Ed 2002; 86:F115-19. doi: 10.1136/fn.86.2.F115.

19. Lipsky MS. Indications for DNR orders: A review. Resid Staff Physician 1986; 32:47-51.

20. Wenger NS, Pearson ML, Desmond KA, Harrison ER, Rubenstein LV, Rogers WH, et al. Epidemiology of do-notresuscitate orders: Disparity by age, diagnosis, gender, race, and functional impairment. Arch Intern Med 1995; 155:2056-62. doi: 10.1001/archinte.1995.00430190042006.

21. Tian J, Kaufman DA, Zarich S, Chan PS, Ong P, AmoatengAdjepong $\mathrm{Y}$, et al. Outcomes of critically ill patients who received cardiopulmonary resuscitation. Am J Resp Crit Care Med 2010; 182:501-6. doi: 10.1164/rccm.200910-1639OC.

22. Beach MC, Morrison RS. The effect of do-not-resuscitate orders on physician decision-making. J Am Geriatr Soc 2002; 50:2057-61. doi: 10.1046/j.1532-5415.2002.50620.x. 
23. Brizzi M, Abul-Kasim K, Jalakas M, Selariu E, PessahRasmussen H, Zia E. Early do-not-resuscitate orders in intracerebral haemorrhage: Frequency and predictive value for death and functional outcome - A retrospective cohort study. Scand J Trauma Resusc Emerg Med 2012; 20:36. doi: 10.1186/1757-7241-20-36.

24. Scarborough JE, Pappas TN. The effect of do-not-resuscitate status on postoperative mortality in the elderly following emergency surgery. Adv Surg 2013; 47:213-25. doi: 10.1016/j. yasu.2013.04.001

25. Resuscitation Council (UK). Do not attempt CPR: Decisions relating to cardiopulmonary resuscitation (3rd edition). From: www.resus.org.uk/dnacpr/decisions-relating-to-cpr/ Accessed: Oct 2015.

26. Onecle. New York Public Health: Article 29-B - Orders not to resuscitate for residents of mental hygiene facilities. From: www.law.onecle.com/new-york/public-health/PBH0A29-B_ A29-B.html Accessed: Oct 2015.

27. American Heart Association. 2005 American Heart Association guidelines for cardiopulmonary resuscitation and emergency cardiovascular care: Part 2 - Ethical issues. Circulation 2005, 112:IV-6-11. doi: 10.1161/CIRCULATIONAHA.105.166551.

28. Teno JM, Branco KJ, Mor V, Phillips CD, Hawes C, Morris J, et al. Changes in advance care planning in nursing homes before and after the Patient Self-Determination Act: Report of a 10-state survey. J Am Geriatr Soc 1997; 45:939-44. doi: 10.1111/j.1532-5415.1997.tb02963.x.
29. Huang $\mathrm{CH}, \mathrm{Hu}$ WY, Chiu TY, Chen CY. The practicalities of terminally ill patients signing their DNR orders: A study in Taiwan. J Med Ethics 2008; 34:336-40. doi: 10.1136/ jme.2007.020735

30. Jaing TH, Tsay PK, Fang EC, Yang SH, Chen SH, Yang CP, et al. "Do-not-resuscitate" orders in patients with cancer at a children's hospital in Taiwan. J Med Ethics 2007; 33:194-6. doi: 10.1136/jme.2006.016360.

31. Masuda Y, Fetters M, Shimokata H, Muto E, Mogi N, Iguchi A, et al. Outcomes of written living wills in Japan: A survey of the deceased ones' families. Bioethics Forum 2001; 17:41-52.

32. Ballin NH. [Do-not-resuscitate orders: Ethical and legal considerations]. Ugeskr Laeger 2007; 169:1201-4

33. The Saudi Commission for Health Specialties, Department of Medical Education \& Postgraduate Studies. Code of ethics for health care practitioners. From: www.scfhs.org. sa/Reglations/CR/uments/\%D8\%A3\%D8\%AE\%D9\%84\%D 8\%A7\%D9\%82\%D9\%8A\%D8\%A7\%D8\%AA\%20\%D8\%A7 \%D9\%84\%D9\%85\%D9\%85\%D8\%A7\%D8\%B1\%D8\%B3\%20 \%D8\%A7\%D9\%84\%D8\%B5\%D8\%AD\%D9\%8A.pdf Accessed: Oct 2015.

34. Knox C, Vereb JA. Allow natural death: A more humane approach to discussing end-of-life directives. J Emerg Nurs 2005; 31:560-1. doi: 10.1016/j.jen.2005.06.020.

35. Mack JW, Paulk ME, Viswanath K, Prigerson HG. Racia disparities in the outcomes of communication on medical care received near death. Arch Intern Med 2010; 170:1533-40. doi: 10.1001/archinternmed.2010.322. 